\title{
Postdispersal Removal and Germination of Seed Dispersed by Cercopithecus nictitans in a West African Montane Forest
}

\author{
Hazel M. Chapman ${ }^{a}$ Stephen L. Goldson ${ }^{b} \quad J_{0}$ sie Beck ${ }^{a}$ \\ a University of Canterbury School of Biological Sciences, ${ }^{b}$ AgResearch, \\ Christchurch, New Zealand
}

\author{
Key Words \\ Cercopithecus nictitans - Germination - Directed dispersal - Nigerian montane \\ forest $\cdot$ Secondary seed dispersal $\cdot$ Seed predation
}

\begin{abstract}
Factors that determine the effectiveness of primates as seed dispersers include (i) the microsite into which they deposit seed, (ii) secondary removal of seed by other taxa and (iii) the effect of gut passage and/or spitting on subsequent seed germination. This contribution evaluated these factors in the little studied putty-nosed monkey, Cercopithecus nictitans, in a Nigerian montane forest. Field experiments showed that $C$. nictitans has greatly increased in its importance as a disperser of medium-sized seed ( $>5 \mathrm{~mm}$ ) because other large primates have been hunted to near extinction. C. nictitans disperses seed across habitats by spitting and defaecation. Rates of secondary seed removal were high for all seed species irrespective of the presence or absence of $C$. nictitans faecal matter, size or microsite variables. Gut passage enhanced germination relative to hand-cleaned seed, while spitting had either no effect or decreased the germination rate.

Copyright $\odot 2010$ S. Karger AG, Basel
\end{abstract}

\section{Introduction}

It is well established that primates play a key role in seed removal and dispersal in tropical forest trees [Gautier-Hion, 1984; Chapman, 1989; Wrangham et al., 1994; Kaplin and Lambert, 2002; Lambert and Chapman, 2005], where up to $90 \%$ of the tree and shrub species produce fleshy fruits adapted for animal dispersal and, as such, provide important primate food resources.

\begin{tabular}{ll}
\hline KARGER & @ 2010 S. Karger AG, Basel \\
Fax +41 61 306 12 34 & \\
$\begin{array}{l}\text { E-Mail karger@karger.ch } \\
\text { www.karger.com }\end{array}$ & $\begin{array}{l}\text { Accessible online at: } \\
\text { www.karger.com/fpr }\end{array}$
\end{tabular}

Hazel Chapman, School of Biological Sciences

University of Canterbury, PB 4800

Christchurch, 8140 (New Zealand)

Tel. +64 3364 2987, ext. 7659, Fax +64 33642590

E-Mail hazel.chapman@canterbury.ac.nz 
In general, in tropical forest ecosystems, as seed size increases there is a predictable decrease in the availability of suitably wide-gaped frugivore species able to ingest and disperse them [Wheelwright, 1985; Chapman et al., 1992; Peres and van Roosmalen, 2002; Gross-Camp et al., 2009]. Furthermore, due to the loss of some primate species through the effects of hunting and deforestation, those that remain have become commensurably more significant as predominant dispersers of medium- (from $>5$ to $\leq 25 \mathrm{~mm}$ ) and large-sized $(>25 \mathrm{~mm}$ ) seeds [Wright et al., 2007]. This situation applies to Nigerian montane forests (i.e. $>1,500$ m elevation), where a previously common large-gaped primate, the Nigerian/Cameroon chimpanzee (Pan troglodytes ellioti) [Matschie, 1914, cited in Oates et al., 2009], is now rare [Kormos and Bakarr, 2003]. However, the ecological effects of this decline may be partially offset, in some forests, by the compensatory presence of the more resilient, arboreal puttynosed monkey (Cercopithecus nictitans) [Chapman et al., 2004]. Other potential primate dispersers of medium and large fruit in Nigerian Afromontane forests include the olive baboon Papio anubis, which Kunz and Linsenmair [2008] have shown to potentially disperse seed of up to $27 \mathrm{~mm}$ and the tantalus monkey (Chlorocebus tantalus tantalus) which ingests and deposits intact seed of up to $22 \mathrm{~mm}$ [Agmen et al., 2009]. However, P. anubis is uncommon at the study site discussed in this contribution, and C. t. tantalus is associated with the forest edge [Agmen et al., 2009]. In contrast, C. nictitans forages throughout Ngel Nyaki forest, as do chimpanzees.

P. troglodytes in montane forest in Uganda disperse seed ranging from $1 \mathrm{~mm}$ in length to $27.4 \mathrm{~mm}$ [Wrangham et al., 1994]. Associated with this contribution, seeds ranging in size from $1 \mathrm{~mm}$ (Ficus spp.) to $30 \mathrm{~mm}$ in length (Pouteria altissima) have been recovered from both $P$. t. ellioti and C. nictitans faecal deposits in Ngel Nyaki forest [H.M. Chapman, unpubl. data].

In spite of the ubiquitous distribution of Cercopithecus spp. (guenons) in African forests, there is evidence that different species of guenon behave differently in terms of diet and seed dispersal, and this, in turn, can be affected by forest type [Kaplin and Moermond, 1998; Chapman et al., 2002; Kaplin and Lambert, 2002]. Given the probable increasing importance of the ecological function of C. nictitans in $\mathrm{Ni}$ gerian montane forests, this paper seeks to update prevailing views on the species' ecological role in forest conservation and regeneration. Such answers have been sought by exploring the following: (1) Does C. nictitans defaecate in any particular forest habitats as described in this study, for example plots with mature, tall trees versus more degraded forest edge plots? (2) Does the presence of $C$. nictitans faecal matter influence the rate of postdispersal seed removal? (3) What other factors affect postdispersal seed removal? (4) Are there differences in the germination rates of seeds that have been defecated by $C$. nictitans, spat out by $C$. nictitans and handcleaned experimentally?

\section{Methods}

\section{Study Site}

The research was conducted in the $46-\mathrm{km}^{2}$ Ngel Nyaki Forest Reserve $\left(7^{\circ} 30^{\prime} \mathrm{N}, 11^{\circ} 30^{\prime} \mathrm{E}\right)$, located on the Mambilla Plateau in Taraba State, Nigeria, at an elevation of approximately $1,550 \mathrm{~m}$. This reserve contains $7.5 \mathrm{~km}^{2}$ of contiguous forest which is the largest on the Plateau [Chapman and Chapman, 2001]. The mean annual rainfall of approximately $1,800 \mathrm{~mm}$ occurs mainly between mid April and mid October (Nigerian Montane Forest Project [NMFP], rain- 
fall data). Mean monthly maximum and minimum temperatures for the wet and dry seasons are 26 and $13^{\circ} \mathrm{C}$, and 23 and $16^{\circ} \mathrm{C}$, respectively [Chapman and Chapman, 2001].

Ngel Nyaki is one of the most floristically diverse montane forest stands in Nigeria [Dowsett-Lemaire, 1989], and at least 4 endangered tree species are common: Entandrophragma angolense, Lovoa trichilioides, Millettia conraui and P. altissima. Resident forest-dwelling primates include the endangered Nigerian chimpanzee (P. t. ellioti) [Beck and Chapman, 2008], the locally uncommon mona monkey (Cercopithecus mona) and the locally common putty-nosed monkey (C. nictitans) [Chapman et al., 2004] which is considered to be the genetically distinct C. nictitans subspecies martini [J.F. Oates, pers. commun.]. Other species (see above) include P. anubis and C. t. tantalus. This forest is an IUCN Important Bird Area and is likely a centre of diversity for amphibian and reptilian species [Blackburn, 2009].

\section{C. nictitans Study Group, Forest Habitat and Microhabitat Identification}

A focal group of semi-habituated C. nictitans ( $\mathrm{n}=$ approx. 20) was studied for 359 days (from November 2005 to December 2006). Each day one of two designated observers followed the group from 6.00 to $12.00 \mathrm{~h}$ and from 16.00 to $18.00 \mathrm{~h}$, and recorded the locations of opportunistically encountered C. nictitans faecal deposits. These defaecations varied from semi-intact deposits on the ground to more dispersed evidence found stuck to foliage and containing seeds.

Forest habitats ranged from disturbed areas sporadically grazed by cattle, usually with a herbaceous or grass understorey, to undisturbed forest comprising tall trees (up to $30 \mathrm{~m}$ in height), with a dense leaf litter layer and comprising little herbaceous understorey. Within each of these major habitats, microhabitats varied mainly according to herbaceous vegetation cover and its height, as well as slope.

In order to investigate (a) the prevalent forest habitat where C. nictitans defaecate (e.g. degraded forest edge vs. established forest) and (b) whether microhabitat variables influence removal rates of dispersed seed, twenty $10 \times 10 \mathrm{~m}$ randomly selected plots, each centred on a C. nictitans faecal deposit, were selected and described. These plots were located across forest habitat types. Within these, 7 environmental variables were measured within each plot using the approach of Gross-Camp and Kaplin [2005]. These variables were chosen to reflect characteristics considered likely to influence (a) C. nictitans foraging behaviour and (b) the removal of $C$. nictitans dispersed seeds.

The first 4 variables were taken from twenty $1 \times 1 \mathrm{~m}$ quadrats randomly placed within each of the $10 \times 10 \mathrm{~m}$ plots. The measurements made were: (i) the numbers of each herbaceous plant species, (ii) the average height $(\mathrm{cm})$ of the herbaceous vegetation, (iii) the percentage of bare ground and (iv) the leaf litter depth. The latter was measured by ascertaining the number of leaves pierced by a wire probe pushed into the soil [Feeley, 2004]. The remaining 3 variables measured once for each $10 \times 10 \mathrm{~m}$ plot were: (i) the slope, using a Suunto handheld clinometer, (ii) the presence of mature trees (trees considered able to produce fruit) and (iii) the average tree diameter at breast height $($ when $>10 \mathrm{~cm}$ ).

To determine whether $C$. nictitans disperses seeds into distinct and preferred habitat types, the same descriptions were repeated for 20 randomly selected plots $(10 \times 10 \mathrm{~m})$ without faecal deposits. The criteria for selection of these were that they were located over $50 \mathrm{~m}$ from any defecation study site and they were the first to be found without any evidence of $C$. nictitans deposits.

A principal component analysis using the MVSP software package version 3.1 [Kovach, 2003] was performed to investigate differences between C. nictitans defaecation and non-defaecation habitats following the rationale of Gross-Kamp and Kaplin [2005]. A spatial ordination of the sites was created using the environmental variables (see above) as well as the slope, presence/absence of mature trees and mean diameter at breast height of trees at each site. The data were $\log$ e transformed in order to meet better the assumption of normality.

Removal of C. nictitans Distributed Seeds

Five actively fruiting tree species were chosen for an experiment seeking to investigate the removal of seeds dispersed by $C$. nictitans. Each seed species was identified as being a common 
Table 1. Seed species and family, seed dimensions and average number of seeds in faecal samples and spits

\begin{tabular}{lllllllr}
\hline Species & Family & $\mathrm{n}$ & $\begin{array}{l}\text { Mean seed size } \\
\text { length } \times \text { breadth) } \\
\text { mm }\end{array}$ & $\mathrm{n}$ & $\begin{array}{l}\text { Mean } \\
\text { number } \\
\text { per faecal } \\
\text { sample }\end{array}$ & $\begin{array}{l}\mathrm{n} \\
\text { pean } \\
\text { per spit }\end{array}$ \\
\hline $\begin{array}{l}\text { Isolona pleurocarpa } \\
\text { Santiria trimera }\end{array}$ & Annonaceae & 20 & $22.3(2.4) \times 12.5(1.8)$ & 12 & $3.3(1.4)$ & 7 & $3.9(2.1)$ \\
Celtis gomophylla & Burseraceae & 20 & $24.7(0.1) \times 16.9(0.04)$ & 24 & $2(1.3)$ & 13 & $11.9(6.3)$ \\
Parkia filiciodea & Cannabaceae & 20 & $3.0(0.4) \times 2.0(0.3)$ & 20 & $5(1.4)$ & 1 & 5 \\
Deinbollia pinnata & Fabaceae & 20 & $22(1.6) \times 9.2(0.6)$ & 12 & $2(1.1)$ & - & - \\
Rytigynia umbellulata & Sapindaceae & 20 & $7.0(0.3) \times 5.4(0.2)$ & 16 & $2(1.1)$ & 1 & 5 \\
\hline
\end{tabular}

Figures in parentheses indicate standard deviations.

source of fruit for C. nictitans in Ngel Nyaki forest and comprised a range of seed sizes known to occur in C. nictictans faecal deposits [unpubl. data]. Species fruit size data in this study were obtained by collecting 20 mature fruits from 5 individual trees comprising each of the chosen species. The fruit length and diameter of each of the 20 seeds per species were measured using digital callipers, and the mean length and diameter calculated. Seed size was measured in a similar way; the fruit was cleaned of pulp and 1 seed from each of the 20 fruits from each tree species was measured (table 1).

\section{Seed Numbers in Each C. nictitans Faecal Deposit}

The experiments described below required an estimate of the numbers of seed from each of the tree species found in a typical $C$. nictitans faecal deposit (table 1). This information was acquired by the opportunistic collection of 90 faecal deposits. These samples were taken to the NMFP field laboratory and wet sieved through a $0.5 \mathrm{~mm}$ mesh. Seed species within each deposit recovered were identified where possible, using the NMFP seed collection and their numbers per deposit recorded. Spat seed was also opportunistically collected from the forest floor between January and May 2006.

It has been observed by the authors that after primary dispersal by C. nictitans, a significant component of dispersed seed in the forests is then either removed (predation) or moved (secondary dispersal) by other forest-dwelling species. In order to examine the potential influence of $C$. nictitans faecal matter on such secondary removal rates of deposited seeds, experiments were established in 10 of the 20 plots $(10 \times 10 \mathrm{~m})$ in which $C$. nictitans deposits had been found; the seeds for the experiment were manually extracted from the fruit of the 5 tree species. The plot choice was based on ensuring a representative selection of microhabitats. Each of the 10 plots was divided into quarters, and each quarter was designated as a subplot. The seed removal experiment was conducted in 2 phases. The first was between November 2006 and January 2007 and used 3 seed species (table 1), and the second occurred between March 2007 and May 2007 and used the remaining 2 species (table 1). Each population of the seeds was then divided into 2 groups. One group remained untreated (the control), whereas the other group was rubbed in 1-day-old C. nictitans faecal matter (the treatment) in order to test whether $C$. nictitans faecal odour had any influence on seed removal rates. Both the control and treatment seeds from the 5 tree species were then placed as piles in each of the 4 subplots replicated 10 times (= a total of 400 piles). The size of each seed pile was determined by the mean number of seeds of each species recovered from a single $C$. nictitans defaecation (table 1).

The numbers of seeds from each of the 5 species found to have been removed was recorded every morning between 6.30 and $8.00 \mathrm{~h}$ and in the evening between 16.00 and $18.00 \mathrm{~h}$ for the first 7 days, every morning for 9 days after that, and every second morning for a further 47 days 
resulting in a total of 63 days of seed removal data. The decrease in frequency of observations over time was based on an observed decline in seed removal rate as the experiment progressed.

The significance of observed differences in seed removal rates in the controls and faecal treatments were tested using a Wilcoxon Mann Whitney test after 7 and 63 days. All 8 plot environmental variables, and the presence of faecal matter and seed size were incorporated into a quasi-Poisson regression model to investigate any effects on the observed seed removal rates. The least predictive factors were eliminated with automated backward selection, using the minimum value for Akaike's information criterion as the selection statistic.

\section{Germination Experiments}

The effect of $C$. nictitans gut passage and seed spitting on seed germination rates of the same 5 tree species was investigated via 3 treatments. These were (i) defaecated seed, unwashed, (ii) hand-cleaned seed and (iii) spat seed, unwashed. Sample sizes comprised 20 seeds per treatment and were sown at a depth of $1 \mathrm{~cm}$ into individual plant pots using moist soil collected from the edge of the research forest. These pots were arranged in the NMFP nursery using a randomized block design. They were monitored daily for seedling emergence for 232 days between December 2005 and August 2006. To avoid any confounding genetic influences arising from individual trees, the seeds for each tree species were collected from a number of conspecific trees.

A mean number of days to germination for each species, in relation to treatment, was determined using only seeds that germinated within the experiment's time limits. A binomial generalized linear regression was used to determine any significant treatment effects on the proportion of seeds germinated. All analyses were carried out using the statistical software R, version 2.5.1 [R Development Core Team].

\section{Results}

Habitat Influence on C. nictitans Defaecation

The results of the multivariate principal component analysis showed no differences between defaecation and non-defaecation sites; thus, there was no indication of any 'directed dispersal' by C. nictitans.

\section{Seed Species Characteristics and Seed Removal Rates}

Seed species, mean seed size and average number of seeds per defaecation and spit are presented in table 1 .

Seeds from all 5 tree species were removed at high rates. Of the 400 piles of seed placed on the forest floor, $65 \%$ of the total seeds had been removed by the first week and $88.5 \%$ by the end of the study period (63 days). Eighty one percent of seed removal in the first week occurred between 16.30 and $9.00 \mathrm{~h}$. All of the Parkia filiciodea seed had been removed by 8 days after the start of the experiment and by 30 days for Deinbollia pinnata. After 60 days (the end of the experiment), $10 \%$ of seed remained of Rytigynia umbellulata, 5\% of Celtis gomophylla and 2\% of Santiria trimera.

\section{Influence of Faecal Matter, Seed Size and Microsite Variables on Seed Removal Rates}

The only significant effect of faecal matter on seed removal rates was found in R. umbellulata, where the presence of faecal matter increased seed removal rates by $10 \%(W=475, \mathrm{p}<0.01)$ and $8 \%(W=435, \mathrm{p}<0.001)$ after 7 and 63 days, respectively (fig. 1). Seed size had no effect on removal rates, and no single environmental variable was found to have any significant common effect on the removal rates. How- 

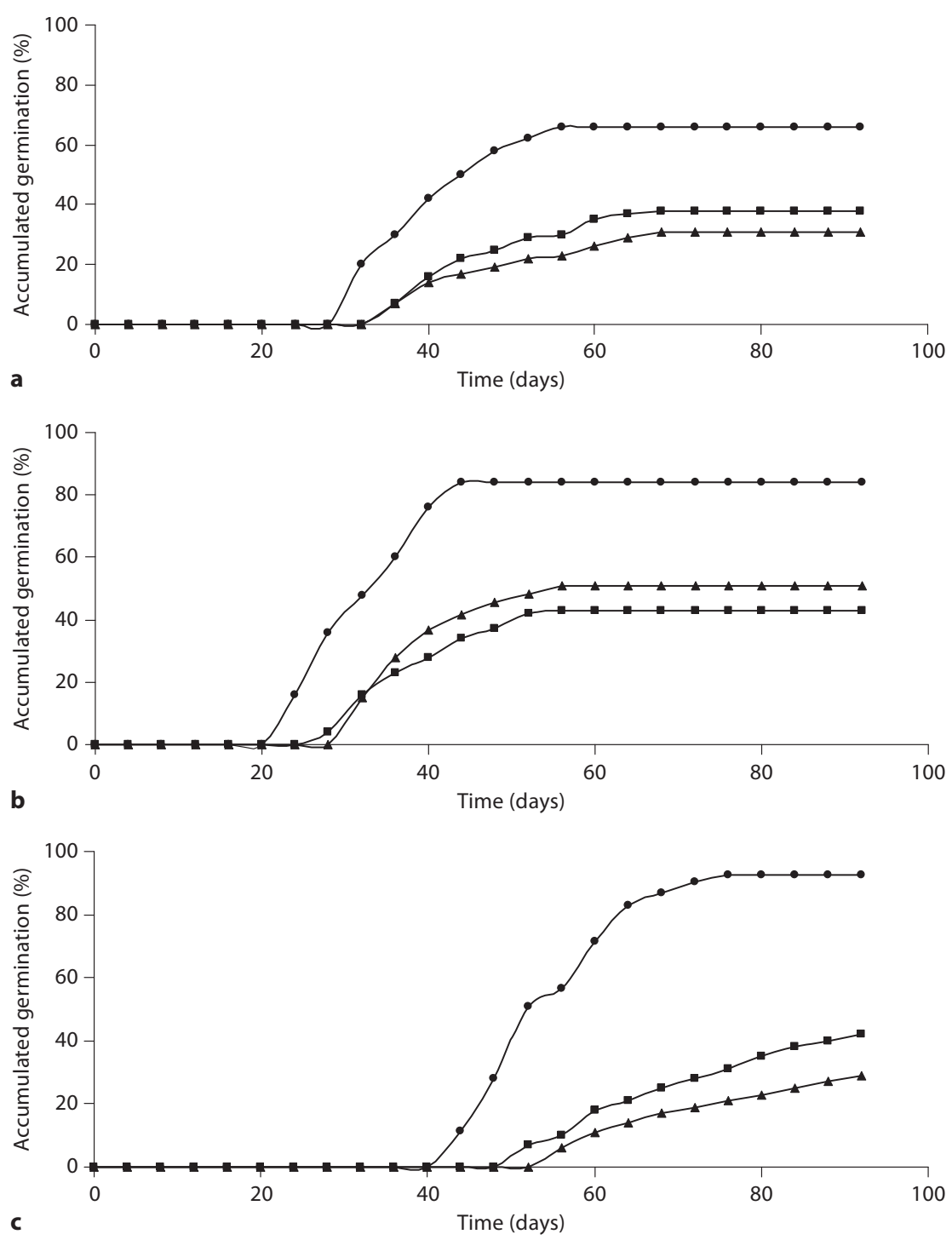

Fig. 1. The percentage of seeds from faeces, spits and ripe fruit germinating in the germination trials, showing the proportion of Deinbollia pinnata (a), Santiria trimera (b) and Isolona pleurocarpa $(\mathbf{c})$ seeds germinating. $\boldsymbol{\Theta}$ = Defaecated seeds; $\boldsymbol{\|}$ = spat seeds; $\boldsymbol{\Delta}$ = seeds hand cleaned of pulp. 
ever, in the case of S. trimera and R. umbellulata, 6 of the variables did explain a small proportion of the variability associated with removal rates. For example, in the case of $S$. trimera, removal rates increased positively with vegetation height $(\mathrm{Z}=8.668$, $\mathrm{p}<0.001)$. Conversely, rates were found to be significantly reduced in the presence of mature trees $(\mathrm{Z}=-14.016, \mathrm{p}<0.001)$. In the case of $R$. umbellulata, the seed removal rate was significantly higher under canopy cover $(Z=9.340, p<0.01)$.

\section{Effects of C. nictitans Gut Passage and Spitting on Seed Germination Rates}

The effect of gut passage on germination rate was positive for 3 of the trial species, i.e. S. trimera $(35 \%, \mathrm{Z}=4.9, \mathrm{p}<0.001)$, D. pinnata $(33 \%, \mathrm{Z}=4.8, \mathrm{p}<0.001)$ and Isolona pleurocarpa (65\%, $\mathrm{Z}=7.772, \mathrm{p}<0.001$; fig. 1$)$. Conversely, in the case of spat seed, the germination rate was either not significantly different to cleaned seed, or, in the case of $S$. trimera, germination was significantly lower $(8 \%, Z=-0.5, p<0.05$; fig. 1).

\section{Discussion}

\section{Primary Dispersal of Viable Seed}

This study has confirmed that the ecological function of $C$. nictitans has characteristics in common with that of other guenons [Chapman et al., 2002]. However, this work has also shown that $C$. nictitans is now a particularly efficient disperser of medium-sized seeds by virtue of its relatively wide gape and its relative abundance compared with other primates in the Ngel Nyaki forest. That there was no detected preference for defaecation in the more open, sporadically grazed versus relatively undisturbed forest habitat means that seeds are widely dispersed by $C$. nictitans. Seeds dispersed into the degraded areas of forest have the potential to contribute to forest regeneration [Lambert and Chapman, 2005; Chapman and Russo, 2007]. Moreover, as some such degraded areas of forest at Ngel Nyaki have recently been protected from grazing and burning, there is a realistic opportunity for regeneration.

\section{Gut Passage and Spitting Effects}

As the result of gut passage, enhanced germination rates compared to clean seed were observed amongst all 3 of the seeds tested. This finding is interesting as not all primates enhance the germination rate of seed they swallow and defaecate intact [Wrangham et al., 1994; Stephenson et al., 2002]. However, several studies have reported increased germination rates for some species after passage through primate guts [Estrada and Coates-Estrada, 1984; Agmen et al., 2009; Valenta and Fedigan, 2009]. Conversely, spitting was found to offer no improvement in germination rate. In fact, spat seed had reduced germination rates in $S$. trimera. This result does not however discount the possibility in other species that spitting (seed cleaning) could enhance seed survival rates in the field, as reported by Lambert [2001].

\section{Secondary Seed Removal Rates}

Seeds from all 5 of the tree species tested in this study underwent high rates of removal, particularly between 16.30 and $9.00 \mathrm{~h}$, and of these, only R. umbellulata showed higher rates of removal in the presence of $C$. nictitans faecal matter. Generally, these results support Feer and Forget [2002], who also found that dung presence 
had no effect on seed fate. While the R. umbellulata result in this study is consistent with other findings where faecal olfactory cues did in fact increase postdispersal seed removal [Chapman, 1989; Shepherd and Chapman, 1998; Andresen, 1999, 2002], it cannot be discounted that this result was more a reflection of the large seed size of $R$. umbellulata, rather than the presence of faecal matter. Nocturnal predators may have been attracted by olfactory cues and found the control seeds because they were relatively close to the seeds exposed to faecal matter. To overcome this problem, a future study should include some plots with only seed exposed to faecal matter and others that are not exposed, as well as some plots with both exposed and unexposed seeds, at the same time controlling for seed numbers.

No environmental effects were found to universally affect all seed species. Indeed, where environmental effects were observed, they were only in association with single species and these effects were consistently weak and sporadic. Seed size or interaction between seed size and the measured environmental variables had no effect on removal rate, which is in contrast to the findings of Forget et al. [1998], who found a positive correlation between seed size and removal rate. This may be because the seed sizes used in this experiment were not as large as those used by Forget et al. [1998] and were too small to attract predators/dispersers. However, the combinations of seed predators and probably dispersers were highly efficient and relatively consistent in locating the seed species tested. The observed seed removal rates in this study were comparable to those reported elsewhere [Andresen, 1999], although different from the finding of Chapman [1995], in Kibale National Park where seed removal rates varied significantly among species, such that the probability of disappearance ranged from 10 to $100 \%$ after 6 months.

Seed removal cannot be attributed to predation only; removal can also result from secondary dispersal [Forget and Millerton, 1991; Andresen, 1999; Vander Wall et al., 2005]. The relative importance of these two influences has been found to depend on a number of factors including season, habitat, forest community and seed characteristics [Andresen, 1999; Vander Wall et al., 2005]. More specifically, seed burial by dung beetles (Scarabidae) has been found to account for a significant proportion of seed removal from frugivore faecal deposits in tropical forests elsewhere [Estrada and Coates-Estrada, 1991; Andresen, 2002]. Such a mechanism is a possibility in Ngel Nyaki forest where, recently, high densities of dung beetles have been recorded [A. Barnes, pers. commun.]. Moreover, seed removal in Ngel Nyaki may also be attributable to rodents, particularly porcupines. Old World porcupines (Hystricidae) are known to scatter hoard [Vander Wall, 1990], and in this study they were frequent nocturnal visitors to the experimental plots, as evidenced by tooth marks on the metal tags marking the quadrats. This is consistent with the finding of Feer and Forget [2002] from the Neotropics that showed that rodents, by scatter hoarding of seeds, effect secondary dispersal. Such behaviour offers seeds a number of advantages, such as escape from pathogens and predation, decreased interspecific competition and deposition into favourable microsites [Forget, 1990; Forget and Millerton, 1991; Stoner et al., 2007]. In view of the above, the role of rodents in seed dispersal in African forests is worthy of more formal investigation as secondary seed dispersal by rodents in African forests has not been documented to date [Stoner et al., 2007]. 


\section{Conclusion}

In general, this work has shown that $C$. nictitans has the potential to play an important role in the maintenance and restoration of Ngel Nyaki forest and, by extrapolation, other Nigerian montane forests, because they are still common relative to other large primates. This advantage of large-bodied frugivores comes primarily from large seed dispersal via defaecation and gut passage and the provision of opportunity for secondary dispersers to move seed around. This study has advanced the understanding of the ecological role of $C$. nictitans and tests assumptions about the monkey's fruit-frugivore impacts within Afromontane forests. Such findings should contribute to the development of effective strategies essential to the conservation and re-establishment of forest remnants in West African forests.

\section{Acknowledgments}

We would like to thank Steve Gawaisa for his data contribution, Musa Bawuro and Matt Walters for field assistance, Dr. Jenny Brown for her guidance with data analyses and 3 anonymous reviewers who made valuable comments on an earlier draft of the manuscript. We are grateful to the Taraba State Forest Service for their invitation and permission to conduct research. Financial Support came from the University of Canterbury in the form of a Summer Scholarship to J.B., the North of England Zoological Society and Nexen Nigeria.

\section{References}

Agmen FL, Chapman H, Bawuro M (2009). Seed dispersal by tantalus monkeys (Chlorocebus tantalus tantalus) in a Nigerian montane forest. African Journal of Ecology DOI: 10.1111/j.1365-2028. 2009.01190.x.

-Andresen E (1999). Seed dispersal by monkeys and the fate of dispersed seeds in a Peruvian rainforest. Biotropica 31: 145-158.

Andresen E (2002). Primary seed dispersal by red howler monkeys and the effect of defecation patterns on the fate of dispersed seeds. Biotropica 34: 261-272.

Beck J, Chapman HM (2008). A population estimate of the chimpanzee Pan troglodytes vellerosus in a Nigerian montane forest: implications for conservation. Oryx 42: 448-451.

Blackburn D (2009). www.projectexploration.org/projectfrog.

Chapman CA (1989). Primate seed dispersal: the fate of dispersed seeds. Biotropica 21: 148-154.

-Chapman CA (1995). Primate seed dispersal: coevolution and conservation implications. Evolutionary Anthropology 4: 74-82.

Chapman CA, Russo SE (2007). Primate seed dispersal: linking behavioral ecology and forest community structure. In Primates in Perspective (Campbell CJ, Fuentes AF, MacKinnon KC, Panger M, Bearder S, eds.), pp 510-525. Oxford, Oxford University Press.

Chapman CA, Chapman LJ, Cords M, Gathua JM, Gautier-Hion A, Lambert JE, Rode K, Tutin CEG, White LJT (2002). Variation in the diets of Cercopithecus species: differences within forests, among forests, and across species. In The Guenons: Diversity and Adaptation in African Monkeys (Glen ME, Cords M, eds.), pp 325-350. New York, Springer.

-Chapman CA, Chapman LJ, Wrangham R, Hunt K, Gebo D, Gardner L (1992). Estimators of fruit abundance of tropical trees. Biotropica 24: 527-531.

Chapman HM, Olson S, Trumm D (2004). An assessment of changes in the montane forests of Taraba State, Nigeria, over the past 30 years. Oryx 38: 1-9.

Chapman JD, Chapman HM (2001). The Forests of Taraba and Adamawa States, Nigeria: An Ecological Account and Plant Species Checklist. Canterbury NZ, University of Canterbury.

Dowsett-Lemaire F (1989). Physiography and vegetation of the highland forests of eastern Nigeria. Tauraco Research Report 1: 6-12.

Estrada A, Coates- Estrada R (1984). Fruit eating and seed dispersal by howling monkeys (Alouatta palliata) in the tropical rain forest of Los Tuxtlas, Mexico. American Journal of Primatology 6: 77-91. 
Estrada A, Coates-Estrada R (1991). Howler monkeys (Alouatta palliata), dung beetles (Scarabaeidae) and seed dispersal: ecological interactions in the tropical rain forest of Los Tuxtlas, Mexico. Journal of Tropical Ecology 9: 45-54.

Feeley KJ (2004). The effects of forest fragmentation and increased edge exposure on leaf litter accumulation. Journal of Tropical Ecology 20: 709-712.

Feer F, Forget PM (2002). Spatio-temporal variations in post-dispersal seed fate. Biotropica 34: 555-566.

Forget PM (1990). Seed-dispersal of Vouacapoua americana (Caesalpiniaceae) by caviomorph rodents in French Guiana. Journal of Tropical Ecology 6: 459-468.

Forget PM, Millerton T (1991). Evidence for secondary seed dispersal by rodents in Panama. Oecologia 87: 596-599.

Forget P, Millerton MT, Feer F (1998). Patterns in postdispersal seed removal by neotropical rodents and seed fate in relation to seed size. In Dynamics of Tropical Communities (Newbery DM, Prins HHT, Brown ND, eds.), pp. 25-49. Oxford, Blackwell Science.

Gautier-Hion A (1984). La dissémination des graines par les cercopithécidés forestiers africains. Ecological Review (Terre Vie) 39: 159-165.

-Gross-Camp N, Kaplin BA (2005). Chimpanzee (Pan troglodytes) seed dispersal in an Afromontane forest: microhabitat influences on the postdispersal fate of large seeds. Biotropica 37: 641-649.

Gross-Camp ND, Mulindahabi F, Kaplin BA (2009). Comparing the dispersal of large-seeded tree species by frugivore assemblages in tropical montane forest in Africa. Biotropica 41: 442-451.

Kaplin BA, Lambert JE (2002). Effectiveness of seed dispersal by Cercopithecus monkeys: implications for seed input into degraded areas. In Seed Dispersal and Frugivory: Ecology, Evolution and Conservation (Levey DJ, Silva WR, Galetti M, eds.), pp 351-364. Wallingford, CABI Publishing.

Kaplin BA, Moermond TC (1998). Variation in seed handling by two species of forest monkeys in Rwanda. American Journal of Primatology 45: 83-101.

Kormos R, Bakkar MI (2003). West African Chimpanzees: Status Survey and Conservation Action Plan. Gland, IUCN/SSC Primate Specialist Group, pp 1-217.

Kovach W (2003). Kovach MVSP version 3.1. Pentraeth, Kovach Computing Services.

Kunz BK, Linsenmair KE (2008). The role of the olive baboon (Papio anubis, Cercopithecidae) as seed disperser in a savanna-forest mosaic of West Africa. Journal of Tropical Ecology 24: 235-246.

Lambert JE (2001). Red-tailed guenons (Cercopithecus ascanius) and Strychnos mitis: evidence for plant benefits beyond seed dispersal. International Journal of Primatology 22: 189-201.

Lambert JE, Chapman CA (2005). The fate of primate dispersed seeds: deposition pattern, dispersal distance, and implications for conservation. In Seed Fate: Predation, Dispersal and Seedling Establishment (Forget PM, Lambert JE, Hulme PE, Vander Wall SB, eds.), pp 137-150. Wallingford, CABI International.

Oates JF, Groves CP, Jenkins PD (2009). The type locality of Pan troglodytes vellerosus (Gray, 1862), and implications for the nomenclature of West African chimpanzees. Primates 50: 78-80

Peres CA, van Roosmalen M (2002). Primate frugivory in two species-rich Neotropical forests: implications for the demography of large-seeded plants in overhunted areas. In Seed Dispersal and Frugivory: Ecology, Evolution and Conservation. (Levey DJ, Silva WR, Galetti M, eds.), pp 351-364. Wallingford, CABI Publishing.

R Development Core Team (2005). R: A Language and Environment for Statistical Computing. Vienna, R Foundation for Statistical Computing.

-Stephenson P, Castellanos M, Pizarro JC, Garavito M (2002). Effects of seed dispersal by three ateline monkey species on seed germination at Tinigua National Park, Colombia. International Journal of Primatology 23: 1187-1204.

Shepherd VE, Chapman C (1998). Dung beetles as secondary seed dispersers: impact on seed predation and germination. Journal of Tropical Ecology 14: 199-215.

Stoner KE, Riba-Hernandez P, Vulinec K, Lambert JE (2007). The role of mammals in creating and modifying seed shadows in tropical forests and some possible consequences of their elimination. Biotropica 39: 316-327.

Valenta K, Fedigan LM (2009). Spatial patterns of seed dispersal by white-faced capuchins in Costa Rica: evaluations of distant-dependent seed mortality. Biotropica 2009, E-pub ahead of print.

Vander Wall SB (1990). Food Hoarding in Animals. Chicago, University of Chicago Press.

- Vander Wall SB, Kuhn KM, Beck MJ (2005). Seed removal, seed predation, and secondary dispersal. Ecology 86: 801-806.

Wheelwright NT (1985). Fruit size, gape width, and the diets of fruit-eating birds. Ecology 66: 808-818.

-Wrangham RW, Chapman CA, Chapman LJ (1994). Seed dispersal by forest chimpanzees. Journal of Tropical Ecology 10: 355-368.

Wright JS, Stoner KE, Beckman N, Corlett RT, Dirzo R, Muller-Landau HC, Nuñez-Iturri G, Peres CA, Wang BC (2007). The plight of large animals in tropical forests and the consequences for plant regeneration. Biotropica 39: 289-291. 